\title{
Article
}

Mycosphere

\section{Testing agricultural wastes for the production of Pleurotus ostreatus}

\author{
Thongklang $\mathbf{N}^{1}$ and Luangharn $\mathrm{T}^{1}$ \\ ${ }^{1}$ Center of Excellence in Fungal Research, Mae Fah Luang University, Chiang Rai 57100, Thailand
}

Thongklang N, Luangharn T 2016 - Testing agricultural wastes for the production of Pleurotus ostreatus. Mycosphere 7(6), 766-772, Doi 10.5943/mycosphere/7/6/6

\begin{abstract}
An edible mushroom, Pleurotus ostreatus (oyster mushroom) has a worldwide cultivation and is popular in Thailand where rubber sawdust is traditionally used in its cultivation. However, rubber sawdust is a relatively expensive substrate that affects the price of $P$. ostreatus production. Six different grain media were tested for spawn production. The best spawn production was in Sorghum bicolor (sorghum) media. Five different agricultural wastes for promoting mycelium growth for spawn production were tested. This was followed by sorghum mixed with corn cobs $(16.8317 \mathrm{~mm} /$ day), and sorghum mixed with rice husks $(11 \mathrm{~mm} /$ day $)$. Agricultural wastes for $P$. ostreatus cultivation were also investigated. A comparative study using rubber sawdust, versus rubber sawdust mixed with different supplements of rice straw, rice husks or corncobs to grow $P$. ostreatus was carried out. The fruiting bodies of $P$. ostreatus were produced at room temperature and $70-80 \%$ humidity. The first primordia and fruiting bodies of $P$. ostreatus appeared on day 30 after inoculation. The optimal substrate to cultivate $P$. ostreatus is sawdust + rice husks with an average wet weight harvest of $277.50 \pm 79.74 \mathrm{~g}$ in a 40 day production cycle.
\end{abstract}

Key words - alternative substrates - basidiomycota - optimal condition - Pleurotaceae

\section{Introduction}

The genus Pleurotus (Fries) Kummer (Pleurotaceae, Basidiomycota) has a worldwide distribution and comprises 14 sections and approximately 40 species (Patel et al. 2012, Index Fungorum 2016). The genus is important as it comprises several edible species which also have medicinal properties (Bonatti et al. 2004). Several Pleurotus species are used as dietary food due to their high fiber, protein and mineral content (Reis et al. 2012). These mushrooms produce soluble polysaccharides, phenolics, ascorbic acid, lectins and ergothioneine and in addition to their pharmaceutical properties, these have anti-tumor, anti-oxidant and anti-microbial activities (De Silva et al. 2013, Yang et al. 2013, Mishra et al. 2013, Liang et al. 2013, Deepalakshmi \& Mirunalini 2014).

In Thailand 22 mushroom species are cultivated commercially and many are species of Pleurotus i.e, Pleurotus giganteus, P. ostreatus, and P. eryngii (Thawthong et al. 2014). In addition, $P$. giganteus could be domesticated and introduced (Klomklung et al. 2012). Pleurotus ostreatus (oyster mushroom) is known as Hed Nanglom in Thai. The mushroom has a high potential for cultivation as it has nutritional and medicinal properties for example anti-cancer, antioxidant, anti-tumor, anti-diabetic, anti-hypercholesterolic, anti-arthritic and antimicrobial properties (Bauerova et al. 2009, EI-Fakharany et al. 2010, Weng et al. 2010, Ghaly et al. 2011, Wu et al. 2011, Mirunalini et al. 2012, Vamanu 2012, De Silva et al. 2013, Patra et al. 2013, Devi et al. 
2013). The species is the second most consumed species in the world after the button mushroom (Agaricus bisporus) (Sánchez 2010) and is also popular in Thailand. Sorghum is commonly used in spawn media for mushroom cultivation, however there are many other substrates used instead of sorghum for example kurakkan, maize, paddy, brown rice, yellow corn, wheat, and millet (Pathmashini et al. 2008, Hoa \& Wang 2015). Likewise, rubber sawdust most common substrates used for cultivation of $P$. ostreatus in Thailand. However rubber sawdust increases the price of production as the price is between 0.34-0.57 US Dollar per kilogram (our observation). There are many other substrates/ agricultural wastes can used for P. ostreatus production e.g. cassava peels, cotton seed hulls, coffee husks, wheat straw, barely straw, saw dust and sinar straw (Sánchez 2010, Da Silva et al. 2012, Ajayi et al. 2015, Tesfaw et al. 2015). Agricultural wastes should be explored for alternative cultivation.

The aim of the research was to cultivate Pleurotus ostreatus with various agricultural wastes. A comparative study using rubber sawdust, versus rubber sawdust mixed with different supplements of rice straw, rice husk and corncobs to grow $P$. ostreatus was carried out. In addition, substrates for optimal spawn media production were investigated. The results of this study are presented and their implications for industrial production are discussed.

\section{Materials \& Methods}

\section{Mushroom strains}

A pure culture of Pleurotus ostreatus was isolated from pileus tissues using sterile forceps by plating on to Petri-dishes with potato dextrose agar (PDA) and incubated at $25{ }^{\circ} \mathrm{C}$ for 14 days. The cultures of mushrooms are deposited in Mae Fah Luang University Culture Collection (as MFLUCC 16-0765) and dried fruiting bodies are deposited in Mae Fah Luang University herbarium (MFU herbarium).

\section{Spawn production}

In this study six different grain media were obtained from local market in Thailand, Sorghum bicolor (sorghum), Pennisetum glaucum (L.) R. Br. (millet), Vigna radiata (L.) R. Wilczek, Steve Hurst. (mung bean), Arachis hypogaea Linn (peanut), Phaseolus vulgaris L. (black turtle beans) and Vigna angularis (Willd.) Ohwi \& Ohashi (kidney bean). The bottles containing 50 $\mathrm{g}$ of grains were inoculated with five mycelial plugs of approximately $0.5 \mathrm{~cm}$ diam. from the mycelia colony on PDA plates. The cultures were incubated in the dark at $25^{\circ} \mathrm{C}$. The experiment was carried out in five replicates. The best grain medium, sorghum was used to mix with others agricultural substrates. The ingredients of the five substrates used to determine suitable media for promoting mycelium growth for spawn production are presented in Table 1. Each spawn medium was washed and soaked overnight, water was drained off, and boiled for 15 minutes, and left to cool for 20 minutes. Fifty grams of each spawn medium was placed in the tissue culture bottles, autoclaved at $121^{\circ} \mathrm{C}$ for 15 minutes and left to cool. Before mycelia of P. ostreatus was inoculated, the bottles were shaken to prevent clump formation and to displace the $0.5 \mathrm{~cm}$ diam. mycelium discs from the upper side of the bottles. Tissue culture bottles were incubated in the dark at $25{ }^{\circ} \mathrm{C}$ for 10 days. The linear mycelium length was measured every 2 days for 10 days to calculate the growth rate. All the analyses were carried out in five replicates.

\section{Suitable agricultural wastes for growing Pleurotus ostreatus}

Four different formulae were tested for cultivating Pleurotus ostreatus. Rubber sawdust was used as the main substrate. The sawdust was mixed (w/w) with rice straw, rice husks and corn cob agricultural waste supplements (Table 2). Rice bran, spent brewery grain, flour, pumice sulfate and calcium carbonate were also added. All substrate supplements were manually mixed with $70 \%$ moisture. The mixture ( $800 \mathrm{~g}$ ) was packed into polypropylene bags then capped with a plastic ring and lid. The sawdust bags were sterilized at $121{ }^{\circ} \mathrm{C}$ for 15 minutes or at $90-100{ }^{\circ} \mathrm{C}$ for $3 \mathrm{hr}$. After the temperature cooled to $25^{\circ} \mathrm{C}$, spawn was inoculated to the sawdust bags, and appropriately $5 \mathrm{~g}$ 
Table 1 The composition of spawn media.

\begin{tabular}{llllll}
\hline \multirow{2}{*}{ Nutritional reagents } & \multicolumn{5}{l}{ The composition of spawn media (g/bottle) } \\
\cline { 2 - 6 } & Sorghum & Sawdust & $\begin{array}{l}\text { Corn } \\
\text { cobs }\end{array}$ & Rice straw & $\begin{array}{l}\text { Rice } \\
\text { husks }\end{array}$ \\
\hline Sorghum & 50 & & & - & - \\
Sorghum+Sawdust & 25 & 25 & - & - & - \\
Sorghum+Corn cobs & 25 & - & 25 & - & - \\
Sorghum+Rice straw & 25 & - & - & 25 & 25 \\
Sorghum+Rice husks & 25 & - & - & - & \\
\hline
\end{tabular}

Table 2 The ratio of experimental substrates (w/w) for cultivation of Pleurotus ostreatus.

\begin{tabular}{ll}
\hline \multicolumn{1}{c}{ Treatments (w/w) } & Quantity/Bag (g) \\
\hline Sawdust & 800 \\
Sawdust + Corn cobs (1:1) & 800 \\
Sawdust + Rice straw (1:1) & 800 \\
Sawdust + Rice husks (1:1) & 800 \\
\hline
\end{tabular}

of mushroom spawn were inoculated into the sawdust bags under aseptic conditions. The bags were incubated in the dark in the mycelial running room temperatures $\left(25 \pm 1{ }^{\circ} \mathrm{C}\right)$, at $60-75 \%$ relative humidity. All analyses were carried out from four replicates. After the mycelial had completely colonized the bag substrates, they were removed from the shelves and opened at the ends. The bags were maintained at $25 \pm 1{ }^{\circ} \mathrm{C}, 70-80 \%$ humidity. Watering was carried out every morning and evening by using a sprayer with tap water until the fruiting bodies had fully developed.

\section{Yield data and statistical analysis}

The mycelia growth rate of $P$. ostreatus in spawn culture was determined and the data analyzed statistically in terms of variance of means by using Tukey's test with significant for $\mathrm{P}<$ 0.05 . The fruiting bodies that matured were manually collected, counted and measured daily. The mushrooms were harvested and recorded for 40 days. The data set was analyzed statistically for variance of means by one-way ANOVA analysis by using Tukey's test. Differences were considered significant for $\mathrm{P}<0.05$.

\section{Results}

\section{Effect of grain media for spawn production}

Optimal growth occurred in the sorghum medium after incubation at $25{ }^{\circ} \mathrm{C}$ for 14 days. Sorghum mixed with different agricultural wastes was tested for promoting mycelia growth and spawn production. After 10 days of incubation, $P$. ostreatus mycelium was able to colonize all spawn media and agricultural waste. The data for mycelium growth on different spawn media were investigated and is shown in Table 3. Sorghum mixed with corn cobs had the highest growth rate $(16.83 \mathrm{~mm} /$ day $)$, followed by sorghum mixed with rice husks $(11.07 \mathrm{~mm} /$ day $)$, sorghum $(8.11$ $\mathrm{mm}$ /day), sorghum mixed with rice straw $(5.27 \mathrm{~mm} /$ day) and sorghum mixed with sawdust $(4.42$ $\mathrm{mm}$ /day). Therefore, the results showed that the various supplemented cereal grain media can be used in order to promote mycelia growth of P. ostreatus.

\section{Suitable agricultural wastes for mushroom production}

The fruiting bodies of $P$. ostreatus were manually harvested and measured daily. The mushrooms were produced at room temperature in $70-80 \%$ humidity. Sawdust, sawdust + corn cobs, sawdust + rice straw and sawdust + rice husks were used for the fruiting body production of $P$. ostreatus. We found that the mushroom grew in all media. The first primordia and fruiting bodies of the $P$. ostreatus appeared on day 30 in sawdust + rice husks media after inoculation (Fig. 1). We found that the best substrate was sawdust + rice husks with an average wet weight of 277.50 
Table 3 Effect of different types of spawn media on mycelia growth rates (mm/day) of P. ostreatus. Values with the same letter are not significantly different $(p<.05)$ in the Tukey's test.

\begin{tabular}{lc}
\hline Spawn media & Mycelial growth rate \\
\hline Sorghum & $8.11 \pm 0.29^{\mathrm{c}}$ \\
Sorghum + Sawdust & $4.42 \pm 0.24^{\mathrm{d}}$ \\
Sorghum + Corn cobs & $16.83 \pm 0.89^{\mathrm{a}}$ \\
Sorghum + Rice straw & $5.27 \pm 0.19^{\mathrm{d}}$ \\
Sorghum + Rice husks & $11.07 \pm 0.46^{\mathrm{b}}$ \\
\hline
\end{tabular}
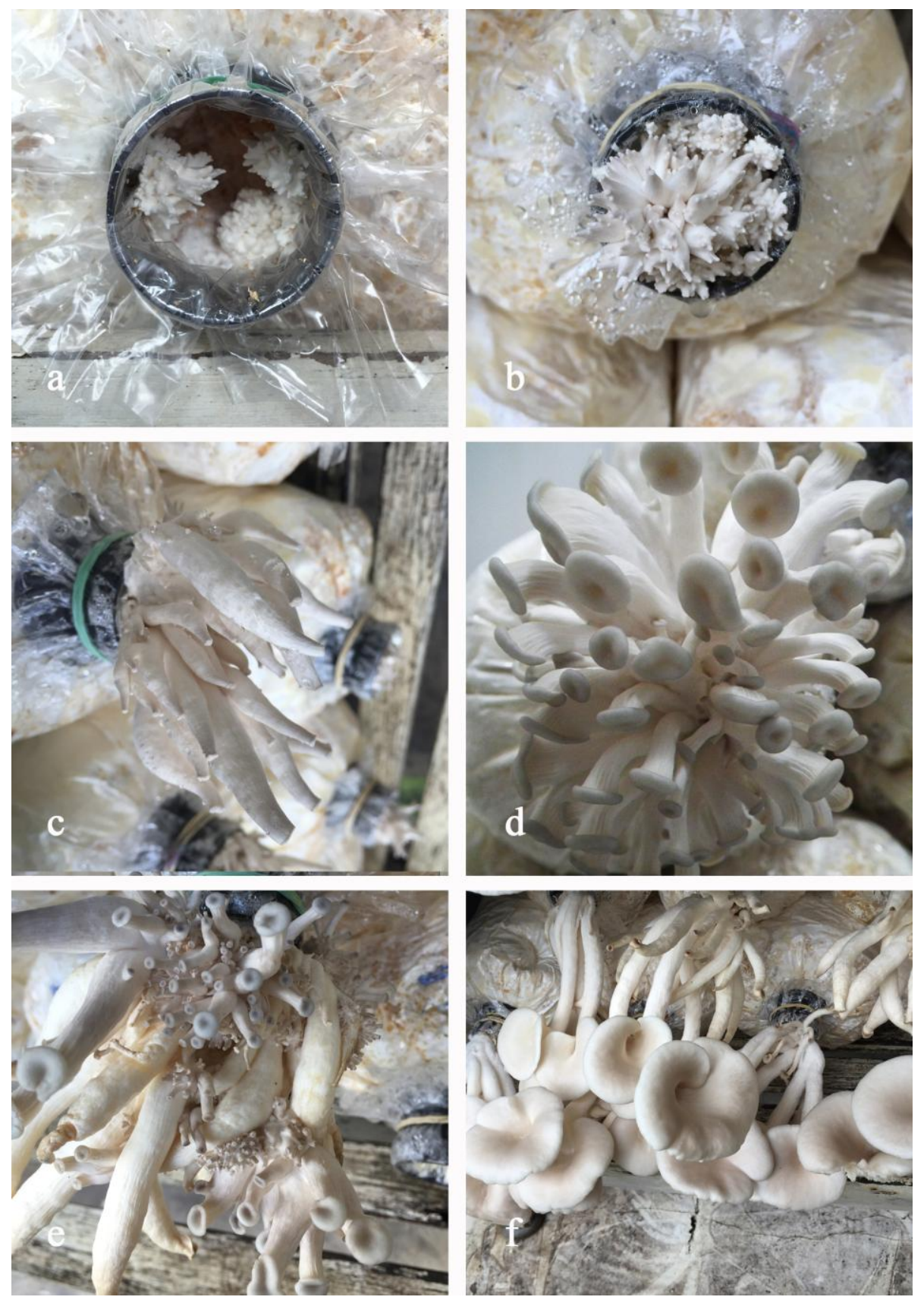

Fig. 1 - The first primordia of $P$. ostreatus appeared on day 30 on sawdust + rice husks media.

$\pm 79.74 \mathrm{~g}$ of $P$. ostreatus fruiting bodies in 40 days, followed by sawdust + rice straw, sawdust + corn cobs and sawdust as the wet yields were $262.50 \pm 45.73 \mathrm{~g}, 175.00 \pm 64.55 \mathrm{~g}$ and $162.50 \pm$ 28.72 respectively in 40 days of production cycle. 


\section{Discussion}

In mushroom cultivation, sorghum grain is frequently used for spawn production and costs 0.23-0.57 US Dollar per kilogram. However, cereal grains such as red bean, black bean $(0.43-0.57$ USD per kilogram), mung bean (0.57-0.99 USD per kilogram), soy bean (0.85-1.14 USD per kilogram), kurakkan, maize (0.23-0.43 USD per kilogram), paddy (0.09-0.14 USD per kilogram), corn (0.43-0.57 USD per kilogram), wheat (2.55-3.97 USD per kilogram), barley (1.42-1.70 USD per kilogram) and millet (0.85-1.14 USD per kilogram) could also be used for spawn production (Pathmashini et al. 2008, Klomklung et al. 2012, Sofi et al. 2014). This study confirms that $P$. ostreatus can grow on all types of grain media and grain media mixed with agricultural wastes (i.e. corn cobs, rice husks, rice straw, sawdust). Optimal growth was found in sorghum + corn cobs spawn media after 10 days of incubation. Thus, agricultural waste can be utilized as substrates for spawn production to decrease the price of mushrooms.

Oyster mushrooms can be cultivated on several substrates including paddy straw, maize stalks/cobs, vegetable plant residues and bagasse (Alemu \& Fisseha 2015). In our fruiting trials, $P$. ostreatus produced fruiting bodies in sawdust + rice husks, sawdust + rice straw, sawdust + corn cobs and sawdust, indicating that Thai agricultural and industrial waste can be used as substrates for cultivation. Sawdust + rice husks had the highest yield and fastest mycelial growth rate. Obodai et al. (2003) also reported that P. ostreatus grew fastest in rice husks bags. Yang et al. (2013) observed that $80 \%$ cotton seed hull mixed with $20 \%$ wheat bran produced significantly larger pilei, followed by $45 \%$ cotton seed hull $+45 \%$ rice straw $+10 \%$ wheat bran and $40 \%$ cotton seed hull + $40 \%$ wheat straw $+20 \%$ wheat bran. In our study the largest pileus diameter was produced in sawdust, followed by sawdust + corn cobs, sawdust + rice husks and sawdust + rice straw. In both studies the addition of agricultural waste was better than the traditionally used substrates, i.e. sorghum alone for spawn production, sawdust + rice husks gave better yields of fruiting bodies than sawdust alone. Therefore the use of agricultural waste has high potential in mushroom production. Thus, further research on how to increase the production yields on sawdust + rice husks substrates by changing the supplement is necessary.

\section{Acknowledgements}

We gratefully acknowledge the International Center for Research in Agroforestry (ICRAF) Vietnam under the "Research Program on Integrated Systems for the Humid Tropics (Humidtropics), Entitled "Research and training for agricultural diversification in Nan" for financial support.

\section{References}

Ajayi O, Adewale O, Micheal I, Mojisola A, Olatundun K, Lettef S, Asagbra Y, Ashiru B, Tomlins K. 2015 - Effect of packaging materials on the chemical composition and microbiological quality of edible mushroom (Pleurotus ostreatus) grown on cassava peels. Food Science and Nutrition 3(4), 284-291.

Alemu F, Fisseha M. 2015 - Cultivation of Pleurotus ostreatus Mushroom on Ficus vasta Leaves (Solid waste of plant) at Dilla University Ethiopia. International Journal of Applied Science 2, 6-19.

Bauerova K, Paulouicova E, Mihalava D, Svik K, Ponist S. 2009 - Study of new ways of supplementary and combinatory therapy of rheumatoid arthritis with immunomodulators Glucomannan and Immunoglukan in adjuvant arthritis. Toxicology and Industrial Health 25, 329-335.

Bonatti M, Karnoppa P, Soaresb HM, Furlana SA. 2004 - Evaluation of Pleurotus ostreatus and Pleurotus sajor-caju nutritional characteristics when cultivated in different lignocellulosic wastes. Food Chemistry 88, 425-428. 
Da Silva MCS, Naozuka J, da Luz JMR, de Assunção LS, Oliveira PV, Vanetti MCD, Bazzolli DMS, Kasuya MCM. 2012 - Enrichment of Pleurotus ostreatus mushrooms with selenium in coffee husks. Food Chemistry 131, 558-563.

De Silva DD, Rapior S, Fons F, Bahkali AH, Hyde KD. 2013 - Medicinal mushrooms in supportive cancer therapies: an approach to anti-cancer effects and putative mechanisms of action. Fungal Diversity 55, 1-35.

Deepalakshmi K, Mirunalini S. 2014 - Pleurotus ostreatus: an oyster mushroom with nutritional andmedicinal properties. Journal of Biochemical Technology 5, 718-726.

Devi KSP, Roy B, Patra P, Sahoo B, Islam SS, Maiti TK. 2013 - Characterization and lectin microarray of an immunomodulatory heteroglycan from Pleurotus ostreatus mycelia. Carbohydrate Polymers 94, 857-865.

EI-Fakharany EM, Haroun BM, Ng TB, Redwan ER. 2010 - Oyster mushroom laccase inhibits hepatitis $\mathrm{C}$ virus entry into peripheral blood cells and hepatoma cells. Protein and Peptide Letters 17, 1031-1039.

Ghaly IS, Ahmed ES, Booles HF, Farang I, Nada SD. 2011 - Evaluvation of antihyperglycemic action of oyster mushroom (Pleurotus ostreatus) and its effect on DNA damage, chromosome aberrations and sperm abnormalities in streptozotocin- induced diabetic rats. Global Veterinaria 7, 532-544.

Hoa HT, Wang CL. 2015 - The Effects of Temperature and Nutritional Conditions on Mycelium Growth of Two Oyster Mushrooms (Pleurotus ostreatus and Pleurotus cystidiosus). Mycobiology 43(1), 14-23.

Klomklung N, Karunarathna SC, Chukeatirote E, Hyde KD. 2012 - Domestication of wild strain of Pleurotus giganteus. Sydowia 60, 39-53.

Liang CH, Ho KJ, Huang LY, Tsai CH, Lin SY, Mau JL. 2013 - Antioxidant properties of fruiting bodies, mycelia, and fermented products of the culinary-medicinal king Oyster mushroom, Pleurotus eryngii (Higher basidiomycetes), with high ergothioneine content. International Journal of Medicinal Mushrooms 15, 267-275.

Mirunalini S, Arulmozhi V, Deepalakshmi K, Krishnaveni M. 2012 - Intracellular biosynthesis and antibacterial activity of silver nanoparticles using edible mushrooms. Journal of Natural Science, Biology and Medicine 4, 55-61.

Mishra KK, Pal RS, ArunKumar R, Chandrashekara C, Jain SK, Bhatt JC. 2013 - Antioxidant properties of different edible mushroom species and increased bioconversion efficiency of Pleurotus eryngii using locally available casing materials. Food Chemistry 138, 1557-1563.

Obodai M, Cleland-Okine J, Vowotor KA. 2003 - Comparative study on the growth and yield of Pleurotus ostreatus mushroom on different lignocellulosic by-products. Journal of Industrial Microbiology and Biotechnology 30, 146-149.

Patel Y, Naraian R, Singh VK. 2012 - Medicinal properties of Pleurotus species (Oyster mushroom): A review. World Journal of Fungal and Plant Biology 3, 1-12.

Pathmashini L, Arulnandhy V, Wilson Wijeratnam RS. 2008 - Cultivation of oyster mushroom (Pleurotus ostreatus) on sawdust. Ceylon Journal of Science 37, 177-182.

Patra S, Patra P, Maity KK, Mandal S, Bhunia SK, Dey B, Devi KSP, Khatua S, Acharya K, Maiti TK, Islam SS. 2013 - A heteroglycan from the mycelia of Pleurotus ostreatus: structure determination and study of antioxidant properties. Carbohydrate Research 368, 16-21.

Reis FS, Barros L, Martins A, Ferreira I. 2012 - Chemical composition and nutritional value of the most widely appreciated cultivated mushrooms: An inter-species comparative study. Food and Chemical Toxicology 50, 191-197.

Sánchez C. 2010 - Cultivation of Pleurotus ostreatus and other edible mushrooms. Applied Microbiology and Biotechnology 85, 1321-1337.

Sofi B, Ahmad M, Khan M. 2014 - Effect of different grains and alternate substrates on oyster mushroom (Pleurotus ostreatus) production. African Journal of Microbiology Research 8, 1474-1479. 
Tesfaw A, Tadesse A, Kiros G. 2015 - Optimization of oyster (Pleurotus ostreatus) mushroom cultivation using locally available substrates and materials in Debre Berhan, Ethiopia. Journal of Applied Biology and Biotechnology 3 (1), 15-20.

Thawthong A, Karunarathna SC, Thongklang N, Chukeatirote E, Kakumyam P, Chamyuang S, Rizal LM, Mortimer PE, Xu J, Callac P, Hyde KD. 2014 - Discovering and domesticating wild tropical cultivatable mushrooms. Chiang Mai Journal of Science 41, 1-34.

Vamanu E. 2012 - In Vitro antimicrobial and antioxidant activities of ethanolic extract of lyophilized mycelium of Pleurotus ostreatus PQMZ91109. Molecules 17, 3653-3671.

Weng TC, Yang YH, Lin SJ, Tai SH. 2010 - A systemic review and meta-analsis on the therapeutic equivalence of stains. Journal of Clinical Pharmacy and Therapeutics 35, 139-151.

Wu JY, Chen CH, Chang WH, Chung KT, Liu YW, Lu FJ, Chen CH. 2011 - Anti-cancer effects of protein extracts from Calvatia lilacina, Pleurotous ostreatus and Volvariella volvacea. Evid based complement. Evidence-Based Complementary and Alternative Medicine, 1-10.

www.indexfungorum.org - 2016

Yang W, Guo F, Wan Z. 2013 - Yield and size of oyster mushroom grown on rice/wheat straw basal substrate supplemented with cotton seed hull. Saudi Journal of Biological Sciences 20, 333-338.

Yang Z, Xu J, Fu Q, Fu X, Shu T, Bi Y, Song B. 2013 - Antitumor activity of a polysaccharide from Pleurotus eryngii on mice bearing renal cancer carbohydrate polymers. Carbohydrate Polymers 95, 615-620. 